\title{
Northwest Territories leads Canada in electronic medical record coverage
}

\author{
Cite as: CMAJ 2017 November 27;189:E1469. doi: 10.1503/cmaj.109-5511
}

Posted on cmajnews.com on Nov. 9, 2017.

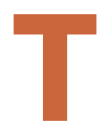
wenty years after a federal advisory committee called for a nationwide health information system to support clinical decision-making, the Northwest Territories (NWT) is on the verge of achieving the elusive dream of having a comprehensive electronic medical record (EMR) system.

"We've now achieved $90 \%$ coverage, and we hope to be fully there within months," said Dr. Ewan Affleck, Chief Medical Information Officer of the Northwest Territories Health and Social Services Authority. "It looks like we'll be the first jurisdiction to achieve this." firmed Simon Hagens, director of benefits realization and quality improvement for Canada Health Infoway, which has received $\$ 2.4$ billion from the federal government since 2001 to help the provinces and territories build their e-health systems. Nunavut is right behind the NWT in implementing a jurisdiction-wide system that makes EMRs available at almost every point of care for most patients, said Hagen.

Infoway officials were unable to provide information indicating where the rest of the provinces stand compared to the NWT and Nunavut in this respect. But in nearby

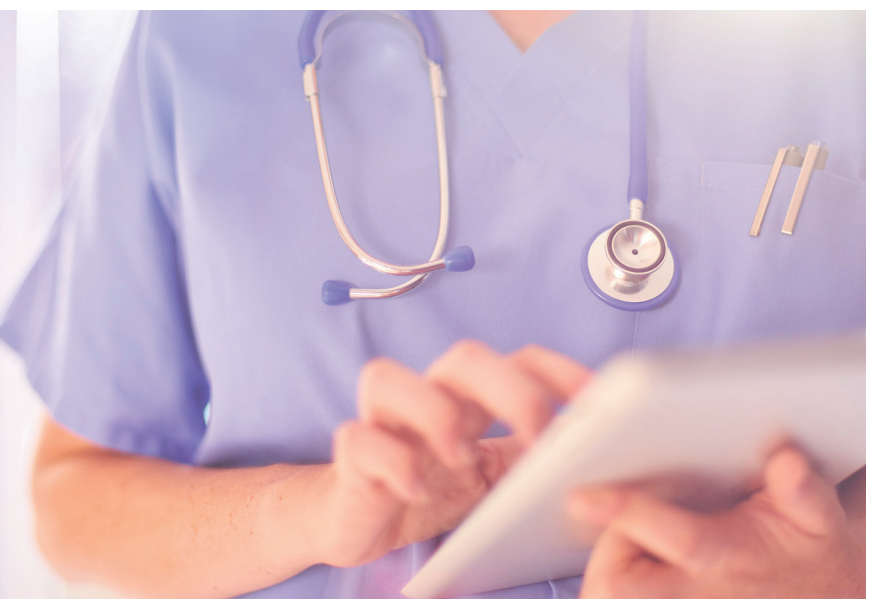

Clinicians in the Northwest Territories can access information for $90 \%$ of patients on a territorywide electronic medical record system.

In preliminary data presented in Toronto last June, Affleck noted that advances in electronic health (e-health) implemented by NWT have already led to improvements in diabetes care and the management of colorectal cancer. "It's still early to have collected convincing data," said Affleck, "but we are increasingly confident the EMR is making a major public health contribution."

When it comes to e-health coverage, the North does indeed lead the country, con-
Alberta, a May 2017 audit described e-health integration as a complicated tangle involving over 1300 clinical and administrative information systems, at a cost of more than $\$ 600$ million a year. If Alberta Health Services was a bank, the audit suggested, each branch would have its own IT system and would communicate by fax.

The NWT's lead over the rest of Canada can largely be ascribed to a 2005 decision to adopt a single EMR system and to "ramp it up into hospitals, clinics and home care settings in every community in the territory," said Vincent Li, manager of technical services for the Yellowknife Health and Social Services Authority. "We negotiated an all-you-can-eat licence" with the EMR vendor, said $\mathrm{Li}$, "and then we hired a contractor to devise the technical architecture and manage the project."

Twelve years later, with financing shared between Infoway and the NWT government, $90 \%$ of the population has an EMR chart that can be seen in 500 points of care. "The only communities we haven't yet rolled it out to are very remote ones where broadband connection or travel access is a barrier," said Li.

That almost all physicians are salaried employees in the territory has made EMR implementation simpler, said Li. "We had the ability to dictate what system they used."

The EMR is especially valuable given the itinerant nature of many patients in the North, said Rebecca Nash, manager of health services for four communities in the Tłı̨cho region with a total population of 3000 . "In the past, we were constantly on the phone trying to locate information about medication, specialists' reports. We can now devote that time to patient care," said Nash.

The EMR allows clinicians to follow every aspect of care closely, and has saved the territory money as well. "Prior to the EMR, lots of lab tests were being done unnecessarily," said Nash. It's giving us substantial savings from over-ordering tests."

Paul Webster, Toronto, Ont.

Editor's note: Dr. Ewan Affleck is a member of the board of directors of Joule, the Canadian Medical Association subsidiary that owns CMAJ, but was not involved in the editorial decisionmaking process for this article. 